\title{
Anemia to Blood Donors at the National Blood Transfusion Center of Abidjan Cote D'Ivoire
}

\author{
Sekongo Yassongui Mamadou ${ }^{1,}$ *, Kabore Saydou ${ }^{2}$, Yao Kouadio Daniel ${ }^{3}$, Dembele Bamory ${ }^{4}$, \\ Konate Seidou $^{5}$, Dasse Sery Romuald ${ }^{6}$ \\ ${ }^{1}$ Department of Training and Research, National Blood Transfusion Center, Abidjan, Côte d'Ivoire \\ ${ }^{2}$ Laboratory of Quality Control, National Blood Transfusion Center, Abidjan, Côte d'Ivoire \\ ${ }^{3}$ Quality Management System, National Blood Transfusion Center, Abidjan, Côte d'Ivoire \\ ${ }^{4}$ Laboratory of Biology Qualification, National Blood Transfusion Center, Abidjan, Côte d'Ivoire \\ ${ }^{5}$ Director of the NBTC, National Blood Transfusion Center, Abidjan, Côte d'Ivoire \\ ${ }^{6} \mathrm{Head}$ of Immunology-allergology Service, Hospitality and University Center of Cocody, Abidjan, Côte d'Ivoire \\ Email address: \\ sekyass@yahoo.fr (S. Y. Mamadou) \\ ${ }^{*}$ Corresponding author
}

\section{To cite this article:}

Sekongo Yassongui Mamadou, Kabore Saydou, Yao Kouadio Daniel, Dembele Bamory, Konate Seidou, Dasse Sery Romuald. Anemia to Blood Donors at the National Blood Transfusion Center of Abidjan Cote d'Ivoire. European Journal of Clinical and Biomedical Sciences. Vol. 6, No. 1, 2020, pp. 1-4. doi: 10.11648/j.ejcbs.20200601.11

Received: December 28, 2019; Accepted: January 6, 2020; Published: January 16, 2020

\begin{abstract}
Blood transfusion is an essential replacement therapy which many patients benefit from during various medical and surgical pathologies. However, transfusion therapy is associated with complications including the risk of iron deficiency anemia to blood donors in whom the pre-donation haemoglobin dosage is an important parameter of transfusion safety. This study therefore aims to determine the prevalence of anemia among blood donors at Côte d'Ivoire National Blood Transfusion Center. This prospective cross-sectional study took place from September 01 to October 31, 2015 at Abidjan National Blood Transfusion Center in Côte d'Ivoire and concerned 50 samples of regular blood donors excluded solely because of anemia out of a total of 1200 regular donors. After the consultation te excluded donor is then taken on an EDTA tube to perform an haemogram on an automated device and from a dry tube which will be used for the determination of ferritinemia. Statistical analyzes were carried out using Epi Info 6.04, Excel and the Chi-square test. The prevalence of anemia to our blood donor was $3.85 \%$. The $\mathrm{Hb}$ level was significantly lower to women than men $(\mathrm{p}=0.048)$ and more frequent anemia beyond 10 donations. The anemia was hypochromic microcytic to 31 donors $(62 \%)$, hypochromic normocytic to 2 donors (4\%), normochromic normocytic to 17 donors (34\%). Martial assessment was performed to 31 donors and ferritin was lowered to 22 donors indicating the absence of an iron reserve. The prevalence of anemia to Côte d'Ivoire blood donors is 3.85\%. Anemia to regular blood donors is mainly due to an iron deficiency. This deficiency is correlated with sex and the number of donations. Iron IV has been shown to be more effective than oral iron in the treatment of iron deficiency anemia in blood donors.
\end{abstract}

Keywords: Anemia, Blood Donors, National Blood Transfusion Center

\section{Introduction}

Anemia is a public health problem around the world, affecting mostly women and children. Anemia affects 1.62 billion people, which corresponds to $24.8 \%$ of the population $[1 ; 2]$. Blood transfusion is an essential replacement therapy that many patients benefit from during various medical and surgical pathologies. The donation of blood is framed by regulatory texts whose purpose is, on the one hand, to guarantee the safety of blood transfusions made by blood products from these donations and on the other hand to preserve the health of donors [3].

To reduce the infectious risk of transfusion, WHO recommends the use of voluntary but regular blood donors. However, they constitute a population at risk of iron deficiency anemia [4]. To prevent these anemic risks to 
blood donors, it is recommended to limit the number of blood donations to 4 per year, whether or not combined with iron supplementation to those regular donors in certain regions [5]. However, in many countries, particularly in developing countries, these standards are generally not respected $[5 ; 6]$.

In Côte d'Ivoire, the number of regular donors is 60,000 with 170,000 blood samples per year. No evaluation of blood donors excluded for anemia has been done to date. In order to better understand the extent of anemia to our blood donors and to prevent it, we conducted this study whose objective is to determine the prevalence of anemia and its type to the blood donors in Abidjan, Côte d'Ivoire.

\section{Methodology}

This is a transversal prospective study, which took place from 1 September to 31 October 2015, at the quality control laboratory of the CNTS of Abidjan Côte d'Ivoire.

The sampling was systematic random or ad hoc. Donors who met our inclusion criteria and who agreed to participate in the study were recruited during the period of our study.

Among a total of 1,300 regular donors, 50 blood donors were excluded because of anemia.

The procedure for selecting blood donors consisted of administering a quiz that is completed by the donor followed by the medical consultation.

After the consultation, the donor passing this barrier is taken in capillary for the evaluation of the pre-donation haemoglobin which when it is $<12 \mathrm{~g} / \mathrm{dl}$, excluded the donor of the blood donation

The donors selected for the study were taken on an EDTA tube to perform an haemogram on the reference automaton (SYSMEX KX 21N) and on a dry tube for the determination of ferritinemia.

We used two methods for hemoglobin determination, one of which is a quick and reliable simple method for predonated hemoglobin assays, and another is the reference method requiring a hematology automaton. Ferritinemia was performed using the ELISA URIT chain.

Pre-donate haemoglobin assay using the EKF Control Hemoglobin Analyzer that needs just a small sample to provide laboratory-quality results in 25 seconds (haemoglobinometer Hemo_Contol EKF Diagnostic). Incorporated with NXT's innovative micro bowl technology, this state-of-the-art unit produces fast results with minimal loss.

Haemogram $(\mathrm{CBC})$ was performed on the 17-parameter SYSMEX KX 21N Hematology Automaton that uses the cyanide-free method for hemoglobin determination. The device used is automatically calibrated at each ignition and the quality control sample is regularly used.

Assay of ferritinemia is performed using the ELISA chain URIT which is an automaton of Biochemistry and Immunology.

Statistical analyzes were done using Epi Info 6.04, Excel and Chi-square tests.

\section{Result}

Table 1. Distribution of anemic blood donors by sex, age group and number of donations.

\begin{tabular}{llll}
\hline Parameter & & Number $(\mathbf{n = 5 0})$ & Percentage \\
\hline Gender & female & 38 & 76 \\
& male & 12 & 24 \\
Age Group & & sex-ratio: 0,31 & \\
& $18-25$ & 9 & 18 \\
& $26-35$ & 15 & 30 \\
& $36-45$ & 17 & 34 \\
& sup 45 & 9 & 18 \\
Number of Donation & & 50 & 100 \\
& inf 10 & 13 & 26 \\
& 10 à 20 & 23 & 46 \\
& sup 20 & 14 & 28 \\
\hline
\end{tabular}

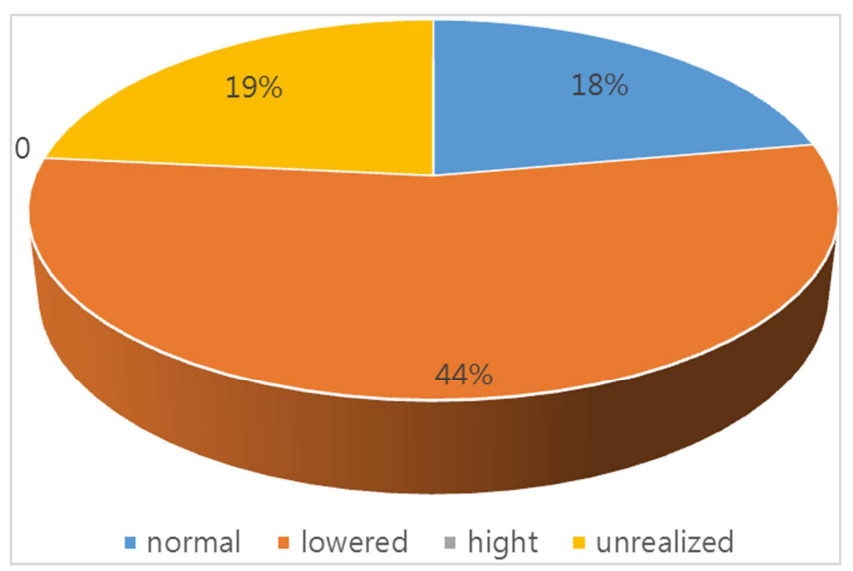

Figure 1. Distribution àf anemic blood donor according the ferritinemia.

Table 2. Distribution of blood donors according to hemoglobin level and the mechanism of anemia.

\begin{tabular}{|c|c|c|c|}
\hline Parameters & & Number $(n=50)$ & Percentage \\
\hline \multirow{2}{*}{ Hb Rate } & $<10 \mathrm{~g} / \mathrm{dl}$ & 39 & 78 \\
\hline & $\geq 10 \mathrm{~g} / \mathrm{dl}$ & 11 & 22 \\
\hline \multirow[t]{3}{*}{$\mathrm{MCV}$} & $<80 \mathrm{fl}$ & 33 & 66 \\
\hline & $80-100 \mathrm{fl}$ & 17 & 34 \\
\hline & $>100 \mathrm{fl}$ & 0 & 0 \\
\hline \multirow[t]{4}{*}{ Mecanisme of the Anemia } & michrocytic hypochromic anemia & 31 & 62 \\
\hline & normocytic hypochromic anemia & 2 & 4 \\
\hline & normochromic normocytic anemia & 17 & 34 \\
\hline & machrocytic anemia & 0 & 0 \\
\hline
\end{tabular}


Table 3. Distribution of anemic blood donors according the treatment.

\begin{tabular}{lll}
\hline Treatment & Number & Percentage \\
\hline Oral iron & 18 & 36 \\
Intravenous iron & 23 & 46 \\
folic acid & 9 & 18 \\
TOTAL & 50 & 100 \\
\hline
\end{tabular}

\section{Discussion}

During the period of our study, we recruited 50 cases of anemia among the 1200 regular donors, a prevalence of $04.17 \%$. Our results remain very low compared to those reported by Diarra A (10\%) in his thesis performed in regular donors in Bamako [7].

The prevalence of anemia to excluded blood donors is $76 \%$ for women and $24 \%$ for men. Our results at the level of women are very close to those of Mohamed A B [8] and Lee CK [9] who obtained respectively to women blood donors, $74 \%$ of aneùia in Mauritania and $.65 \%$ in Hong Kong. Our rate of anemia to female blood donors is higher than that reported by Franck NL and al. [10] who found 58\% of anemia to women blood donors in the Democratic Republic of Congo. Using normal values for hemoglobin $<12 \mathrm{~g} / \mathrm{dl}$ for men and haemoglobin $<11 \mathrm{~g} / \mathrm{dl}$ for women [3] to compare our results with other African countries, the prevalence of Anemia among excluded male donors and excluded female donors is $24 \%$ and $76 \%$, respectively. Our results do not corroborate those of $\mathrm{C}$ Tayou et al [11] who obtained a prevalence of $11.6 \%$ among men in Cameroon, $7.14 \%$ in Côte d'Ivoire $3.5 \%$ in Congo Kinshasa and 3\% in Burkina Faso, while for women this rate is $20.3 \%$ in Cameroon, $5.71 \%$ in Côte d'Ivoire and $10 \%$ in Burkina Faso. This discrepancy is explained by the fact that these data were obtained by a questionnaire and it is not mentioned whether anemia has been diagnosed clinically or biologically.

The average age of our patients was 26 years old with extremes of 18 and 57 years old. The weakness of our average age is due to the fact that the majority of our blood donors are recruited from students. Our results are in agreement with those of Diarra [7] in Mali who reported a prevalence of anemia among blood donors aged 22 to 31 years. The age group of $18-45$ accounted for $82 \%$ of the anemic blood donors and this could be explained by the fact that this age group is the most involved in the blood donation. These results confirm those of $\mathrm{C}$ Tayou et al [11] who obtained a prevalence of $77.2 \%$ among blood donors aged 18 to 39 years.

Indeed the blood donation has a significant effect on the iron reserves of frequent donors and especially women.

The median number of blood donations was 14 with extremes of 3 and 56. Anemia was more common in more than 10 donations. Indeed the blood donation has a significant effect on the reserves hell frequent donors and especially women.

The average interval between each blood donation was 78 days. The majority of donations were made between 60 and 90 days. On the whole, the minimum period of 3 months required between 2 donations was not respected by both blood donors and doctors of the pre-donation consultation. The average $\mathrm{Hb}$ level was $9.6 \mathrm{~g} / \mathrm{dl}$ with extremes of 7.8 and $11.5 \mathrm{~g} / \mathrm{dl}$. Anemia was hypochromic microcytic to 31 donors (62\%), normocytic hypochromia to 2 donors (4\%), and normochromic normochromia to 17 donors (34\%) and macrocytic to no donor. Our results do not corroborate those of Mohamed A. B. [8] who obtained to men, 38\% microcytic anemia, 53\% normochromic normochromic anemia, 9\% macrocytic anemia and in women $36 \%$ microcytic anemia, $60 \%$ normochromic normocytic anemia, 4\% macrocytic anemia. The martial assessment was performed to 31 donors and ferritin was lowered (iron deficiency) to 22 donors (71\%) Indicating the absence of iron reserves. No donors excluded because of anemia had a higher ferritin level. Our results are close to those of Nzungu-Lukuza [10] who found $62.5 \%$ iron deficiency in volunteer blood donors in Congo Kinshasha. These results show that to the regular blood donor, anemia is mainly due to iron deficiency due to regular bleeding. These results confirm those reported by Salvin and al. [12]. Mindy G. et al [13], showed through interviews conducted in their study that most donors are unaware that depletion of iron stores is a possible detrimental consequence of frequent blood donations.

The $\mathrm{Hb}$ level was significantly lower to women than to men $(p=0.048)$. and anemia more frequent in more than 10 donations. These results are identical to those of the Canadian Transfusion Society in 2009-2010.

The American Society of Blood Bank recommends establishing the history of blood donations as part of the investigation of a martial deficiency [14]. According A. M. Fillet; obviously, taking iron supplements, is necessary [15].

Treatment consisted of the administration of iron (oral 18 donors, IV 23 and folic acid 9 donors). After 3 months of follow-up, 22 donors corrected their anemia of which 10 under IV iron, 3 under oral iron and 9 under folic acid.

Intravenous iron has been more effective than oral iron to the treatment of iron deficiency anemia in blood donors. Our results corroborate those of Jiss JE and al [16] and Krayenbuehl PA and al [17].

\section{Conclusion}

The prevalence of anemia to our blood donors is $3.85 \%$ with a clear predominance of women with $76 \%$ against $24 \%$ for men. Anemia to regular blood donors is mainly due to an iron deficiency. This deficiency is correlated with sex and the number of donations. Intravenous iron has been shown to be more effective than oral iron to the treatment of iron deficiency anemia in blood donors. This monitoring made it possible to reintroduce these donors into the blood donation circuit.

Blood donation has a significant effect on the iron stores of frequent donors, especially women. Several measures are necessary to prevent, detect and treat iron deficiency to donors. They include less frequent donations for donors most likely to have a martial deficiency and better information for both donors and their Doctor. 


\section{Interest Conflict}

The authors declare that there is no conflict of interest for this manuscript.

\section{References}

[1] WHO. Haemoglobin concentrations for the diagnosis of anaemia and assessment of severity: Vitamin and Mineral Nutrition Information System. Geneva: World Health Organization; 2011.

[2] McLean E, Cogswell M, Egli I, Wojdyla D, De Benoist B. Worldwide prevalence of anemia, WHO Vitamin and Mineral Nutrition Infromation System, 1993-2005. Public Health Nutr. 2009 Apr; 12 (4): 444-54.

[3] -B. Danic Mise au point. Enoncer les conditions d'un don de sang standard et les motifs d'exclusion. Transfusion clinique et biologique 12 (2005) 287-289.

[4] WHO Sécurité transfusionnelle et approvissionnement en sang. World Health Organization; Juin 2017. https://www.who.int/fr/news-room/fact-sheets/detail/bloodsafety-and-availability.

[5] Jeremiah ZA, Koate BB. Anaemia, iron deficiency and iron deficiency anaemia among blood donors in Port Harcourt, Nigeria. Blood Transfusion. 2010; 8 (2): 113-7.

[6] Mittal R, Marwaha N, Basu S, et al. Evaluation of iron stores in blood donors by serum ferritin. Indian J Med Res. 2006; 124 (6): 641-6.

[7] Diarra A. Anémie chezta les donneurs de sang réguliers au CNTS de Bamako. Thèse, Pharm. Bamako 2006.

[8] Mohamed A. B. Prévalence de l'anémie chez les donneurs de sang au Centre National de Transfusion Sanguine de Nouakchott; Master de Santé Publique 2013.

[9] Lee CK, Wong HK, Hong J, et al. A study of the predonation hemoglobin and iron status among Hong Kong Chinese blood donors. Transfusion. 2013; 53 (2): 322-7.
[10] Franck Nzengu-Lukusa, Sylvain Yuma-Ramazani, Eddy Sokolua-Mvika, Angèle Dilu-Keti, Blanchard MalengaNkanga, Jean Baptiste Shuli, Donatien Kayembe NzongolaNkasu, Ferdinand Mbayo-Kalumbu et Steve Ahuka-Mundeke Carence en fer, anémie et anémie ferriprive chez les donneurs de sang à Kinshasha, République Démocratique du Congo. Pan Afr Med J. 2016; 23: 174.

[11] C. Tayou Tagny, A Diara, RakiaYahaya, M. Hakizamana, A. Nguessan, G. Mbensa, YacoubaNebié, H. Dahourou, J-B. Tapko, S. Shibosky, E. Murphy, J. J. Lefrére. Le centre de transfusion, le donneur de sang, et le sang donné dans les pays d'Afrique francophone. Transfusion clinique et biologique 16 (2009) 431-438.

[12] Salvin HE, Pasricha S, Marks DC, Speedy J. Iron deficiency in blood donors: a national cross-sectional study. Transfusion. 2014; 54 (10): 2434-44. [PubMed] [Google Scholar].

[13] Mindy Goldman, MD, FRCP (C); www.transfusionmedicine.ca/fr Publié en juillet 2013 - Page $1 / 11$.

[14] American Association of Blood Banks. «Strategies to Monitor, Limit, or Prevent Iron Deficiency in Blood Donors », Bulletin no 12-03. Sur http://www.aabb.org/resources/publications/bulletins/Pages/ab 12-03.aspx $>$.

[15] AM Fillet, S. Gross Prevention of anemia in blood donors ransfusion clinique et biologique 2017, 24; 3: 143-147.

[16] Kiss JE, Brambilla D, Glynn SA, Mast AE, Spencer BR, Stone M, Kleinman SH, Cable RG, National Heart L, Blood Institute Recipient E, Donor Evaluation S, III. Oral Iron Supplementation after Blood Donation: A Randomized Clinical Trial. JAMA 2015; 313: 575-83. https://www.ncbi.nlm.nih.gov/pubmed/25668261.

[17] Krayenbuehl PA, Battegay E, Breymann C, Furrer J, Schulthess G. Intravenous Iron for the Treatment of Fatigue in Nonanemic, Premenopausal Women with Low Serum Ferritin Concentration. Blood 2011; 118: 3222-7. https://www.ncbi.nlm.nih.gov/pubmed/21705493. 